\title{
DinÂMICA DE NITROGÊNIO EM UM SISTEMA DE LAGOAS DE ESTABILIZAÇÃO NA REGIÃO DO VALE DO RIBEIRA (SÃo Paulo - Brasil)
}

\author{
NITROGEN DYNAMIC IN WASTE STABILIZATION PONDS SYSTEMS IN THE \\ RIBEIRA's VALLeY REgION (SÃo PAulo - Brasil)
}

\section{Adriana CRISTINa Poli MiWa}

Química, Doutoranda em Hidráulica e Saneamento, Escola de Engenharia de São Carlos, Universidade de São Paulo, Brasil

\section{Rogério HERLON FURTAdo FREIRE}

Químico, Doutorando em Hidráulica e Saneamento, Escola de Engenharia de São Carlos, Universidade de São Paulo, Brasil

\section{MARIA DO CARMO CALIJURI}

Bióloga, Professora Titular do Departamento de Hidráulica e Saneamento, Escola de Engenharia de São Carlos, Universidade de São Paulo, Brasil

Recebido: 28/06/06 Aceito: 12/03/07

\section{RESUMO}

Esta pesquisa teve como principal objetivo investigar os processos envolvidos nas transformaçóes do nitrogênio em um sistema de lagoas de estabilização. Em amostragem nictemeral (24 horas) observou-se forte estratificação térmica durante a maior parte do ciclo amostrado a qual condicionou a compartimentalização vertical e a estratificação química nas duas lagoas, possibilitando a análise dos processos de forma segmentada pela ACP (análise de componentes principais), que mostrou-se ferramenta estatística muito útil na caracterização dos processos. A degradação de proteína, com subseqüente geração e acúmulo de nitrogênio amoniacal, foi observada, além da possível excreção de proteína ou aminoácidos por organismos fitoplanctônicos na superfície das lagoas. A provável ocorrência de nitrificação na superfície da lagoa anaeróbia evidenciou a necessidade de otimização de operação do sistema a fim de viabilizar a remoção de nitrogênio através da desnitrificação, processo provavelmente inibido pelas elevadas concentraçóes de oxigênio dissolvido registradas durante o dia.

PALAVRAS-CHAVE: Lagoas de estabilização, dinâmica do nitrogênio, ciclo nictemeral, Análise de Componentes Principais (ACP).

\section{INTRODUÇÃO}

Os processos que ocorrem no sistema de lagoas de estabilização apresentam uma complexidade intrínseca resultante do acoplamento dos processos de produção e decomposição de matéria orgânica pela microbiota residente, além da influência das alte-

\section{ABSTRACT}

This research had as main objective to investigate the involved processes in the transformations of nitrogen in a system of waste stabilization ponds. In nictemeral sampling (24 hours) strong thermal stratification was observed during most of the showed cycle which conditioned two vertical compartments and the chemical stratification in the two lagoons, making possible the analysis of the processes of segmented form for PCA (Principal Components Analysis) that was a very useful statistics tool in the characterization of the processes. The protein degradation was observed with subsequent generation and accumulation of ammoniacal nitrogen, beyond the possible excretion of protein or amino acids for phytoplanktonic organisms in the surface of the ponds. The probable occurrence of nitrification in the surface layer of the anaerobic pond evidenced the necessity of improving the operation parameters of the system in order to reach a greater nitrogen removal through the denitrification, process probably inhibited by significant high concentrations of oxygen dissolved registered in superficial layers, particularly during the day.

KEYWORDS: Waste stabilization ponds, nitrogen dynamics, nictemeral cycle, principal component analyses (PCA). rações climáticas sobre o metabolismo do sistema. Diante disso, fica claro que a otimização de operação de um sistema de lagoas de estabilização deve levar em conta, além da configuração, geometria e parâmetros hidrodinâmicos, geralmente considerados na fase de projeto como determinantes para a eficiência de remoção desejada, o conhecimento das respostas das lagoas às variações climáticas, incluindo as relações ecológicas intra- e interespecíficas entre as comunidades residentes.

Devido à própria natureza e concepção deste tipo de sistema de tratamento, as lagoas de estabilização, quando bem projetadas e operadas, podem produzir efluentes com excelentes 
condições sanitárias e satisfatória remoção de matéria orgânica, reduzindo o impacto da carga orgânica aos corpos de água receptores. No entanto, o efluente de lagoas de estabilização apresenta, de modo geral, significativas concentraçoes de fósforo e nitrogênio, considerados os principais fatores nutricionais limitantes ao crescimento dos organismos produtores primários em ecossistemas aquáticos. Desta forma, a disponibilidade de nutrientes essenciais pode induzir à eutrofização dos corpos de água receptores, com profundas implicações sobre a qualidade da água, que vão desde mudanças na composição química a alteraçóes na estrutura e funcionamento das comunidades biológicas, incluindo florações de espécies fitoplanctônicas potencialmente tóxicas e aumento da biomassa de macrófitas aquáticas.

Dos nutrientes considerados como fatores limitantes, o nitrogênio merece especial atenção em razão de apresentar, além de formas dissolvidas e particuladas sujeitas a transformações físicas e químicas mediadas ou não por microrganismos, formas voláteis que podem ser interconvertidas dentro do próprio sistema ou fixadas a partir do reservatório atmosférico por espécies metabolicamente habilitadas a realizar este tipo de transformação. Em adição às formas voláteis, o nitrogênio apresenta espécies cineticamente instáveis, como o íon nitrito, intermediário entre os processos de desnitrificação e nitrificação, mediados por alguns gêneros de bactérias. Estes processos são altamente dependentes das condiçôes de oxigenação, $\mathrm{pH}$ e temperatura do meio, variáveis que governarão a transformação e destino do nitrogênio em lagoas de estabilização. Segundo Silva et al (1995), a remoção de nitrogênio é o aspecto chave a ser considerado na tecnologia de tratamento por lagoas de estabilização, de forma que a operação do sistema deve ser otimizada a fim de permitir uma maior eficiência de redução.

Dentre as rotas de transformação do nitrogênio em lagoas de estabilização destacam-se os processos de oxidação e redução, responsáveis pela interconversão entre espécies em diversos estados de oxidação e agregação física (Reed, 1985). Middlebrooks et al (1982) destacaram três mecanismos principais de remoção do nitrogênio em lagoas de estabilização: volatilização da forma não-ionizada do nitrogênio amoniacal
$\left(\mathrm{NH}_{3}\right)$ sob condições favoráveis de temperatura e $\mathrm{pH}$, assimilação e incorporação na biomassa algal e nitrificação biológica acoplada a desnitrificação. Além destes mecanismos, Ferrara \& Avci (1982) consideraram a sedimentação do nitrogênio orgânico como um dos processos efetivos na remoção de nitrogênio nestes sistemas.

Segundo Peng et al (2005), nitrogênio orgânico e amoniacal são as principais formas presentes em águas residuárias. $\mathrm{O}$ nitrogênio orgânico é convertido a amoniacal sob ambas as condições: anaeróbia e aeróbia. A remoção de nitrogênio amoniacal contribui para remoção de nitrogênio total e, temperatura e $\mathrm{pH}$ têm impacto sobre os processos de bioatividade e volatilização.

Segundo Zimmo et al (2003a), há um crescente interesse na modificação de lagoas de estabilização convencionais, tendo o fitoplâncton como principal comunidade produtora, para aquelas colonizadas por macrófitas aquáticas, as quais serviriam como sumidouro de nutrientes e posterior fonte de alimento para animais. Satisfatórias remoções de nitrogênio têm sido observadas em sistemas de lagoas de estabilização com wetlands construídas.

Zimmo (2003b) investigou a dinâmica das formas nitrogenadas e o efeito das variáveis $\mathrm{pH}$ e oxigênio dissolvido em experimentos (incubações em batelada) simulando lagoas de estabilização com organismos fitoplanctônicos e macrófitas aquáticas. Várias rotas de remoção foram propostas, incluindo a assimilação pelos organismos fitoplanctônicos e sedimentação. No entanto, os autores chamaram a atenção para a dificuldade no entendimento dos processos de transformação e fluxo do nitrogênio nos dois tipos de sistema, apesar de reconhecerem a influência do $\mathrm{pH}$ e do oxigênio dissolvido na volatilização da amônia, nitrificação e desnitrificação, assimilação pelos organismos fitoplanctônicos e incorporação na biomassa das macrófitas aquáticas.

Portanto, diante da necessidade de um melhor entendimento dos processos envolvidos na dinâmica das formas nitrogenadas e da influência das variaçôes climáticas ao longo do ciclo diário sobre o funcionamento do sistema de lagoas de estabilização do município de Cajati (São Paulo), foi realizado um estudo contemplando metodologia de amostragem nictemeral. Além da contribuição para o entendimento dos processos envolvidos nas transformaçôes do nitrogênio, a continuidade da pesquisa tem como objetivo principal gerar informações que subsidiem decisões de otimização do sistema com vistas a uma maior eficiência de remoção de nutrientes, atenuando os impactos resultantes do lançamento do efluente das lagoas sobre a qualidade do corpo receptor.

\section{PARTE EXPERIMENTAL}

\section{Área de estudo}

O sistema de lagoas de estabilização investigado é responsável pelo tratamento do esgoto produzido pelo município de Cajati (24043'23" S e 48o05'39" W), localizado no Vale do Ribeira de Iguape (Figura 1), a sudeste do estado de São Paulo (Brasil), com área de aproximadamente $455 \mathrm{~km}^{2} \mathrm{e}$ população estimada em 32.052 habitantes (75\% em área urbana). A rede de abastecimento de água atende a 93\% dos domicílios, sendo que 65\% têm acesso à rede coletora de esgoto. Do total coletado, $90 \%$ são tratados (SABESP, 2005).

O clima da região pode ser classificado como tropical úmido, com temperatura média do ar de $21,5^{\circ} \mathrm{C}$. O período de maior precipitação pluviométrica vai de setembro a março, com o mês de janeiro apresentando a maior média histórica (CETESB, 2004). As médias mensais de precipitação e temperatura do ar correspondentes ao período de estudo desta pesquisa (abril/2005) foram $115 \mathrm{~mm}$ e $24,3^{\circ} \mathrm{C}$, respectivamente (CIIAGRO, 2005).

O sistema de tratamento por lagoas de estabilização surge como alternativa ao tratamento do esgoto produzido pelas cidades da região do Vale do Ribeira, considerada a mais pobre do Estado de São Paulo. A adoção deste sistema pela quase totalidade dos municípios da região justifica-se tanto pela eficiência na remoção de matéria orgânica em diversos estados de agregação e redução significativa na densidade de patógenos como pela compatibilidade com a realidade econômica local. Dentre os municípios dotados com sistema de tratamento por lagoas de estabilização pode-se citar Cajati, Jacupiranga, Pariquera-Açu, Juquiá, São Lourenço da Serra e Registro. 


\section{Descrição da estação de tratamento de esgoto de Cajati (ETE Cajati)}

O esgoto chega a Estação de Tratamento de Esgoto de Cajati (ETE Cajati) por meio de elevatórias e, em seguida, passa por uma etapa de tratamento preliminar (gradeamento e caixa de areia). Posteriormente, este afluente passa por um sistema australiano de lagoas (anaeróbia e facultativa), de onde segue para um tanque de cloração, no final da ETE Cajati, o qual apresenta funcionamento intermitente. $\mathrm{Na}$ Tabela 1 podem ser observados os dados de projeto do sistema.

Devido a problemas de infiltração de água pluvial na rede coletora de esgoto, o sistema de tratamento recebeu uma carga orgânica cerca de 66,0\% inferior à carga original de projeto $\left(5.177,2 \mathrm{kgDBO} \cdot \mathrm{dia}^{-1}\right)$.

\section{Material e métodos}

A amostragem foi realizada em abril de 2005 e seguiu metodologia de coleta nictemeral (24) com amostras coletadas a cada 6 horas, sendo a primeira às 8 horas da manhã (T0), seguida de 14h (T1), 20h (T2), 2h (T3) e 8h (T4), fechando o ciclo diário de amostragem. As amostras para análise de nitrogênio total Kjeldahl, nitrogênio amoniacal, nitrato, nitrito e proteína foram coletadas em profundidades correspondentes à sub-superfície $(S)$, meio $(M)$ e interface água-sedimento $(\mathrm{F})$ das respectivas estaçôes amostradas com auxílio de garrafa de van Dorn. Foram amostradas 4 estaçóes, sendo duas em cada lagoa, como mostra a Figura 2. Com exceção da determinação de proteína, que seguiu Lowry et al (1951), as demais variáveis foram analisadas seguindo metodologia analítica descrita em APHA (1999).
Os perfis verticais das variáveis temperatura, $\mathrm{pH}$ e oxigênio dissolvido foram determinados com auxílio de uma sonda YSI 556, previamente calibrada, em intervalos regulares da coluna de água $(0,10 \mathrm{~m})$. As amostras para análise de nutrientes dissolvidos foram filtradas em campo em filtros de fibra de vidro $(0,2 \mu \mathrm{m})$ e mantidas congeladas até a realização das determinações analíticas em laboratório. As determinações de nitrogênio total Kjeldahl e proteína foram realizadas em amostras não filtradas, também preservadas sob congelamento.

As amostras para determinação da densidade total do fitoplâncton foram coletadas na sub-superfície, meio da coluna de água e interface água-sedimento, sendo preservadas com solução de formol a 4,0\% e mantidas ao abrigo da luz até o momento da contagem. A densidade fitoplanctônica foi determinada segundo Wetzel \& Likens (1991).

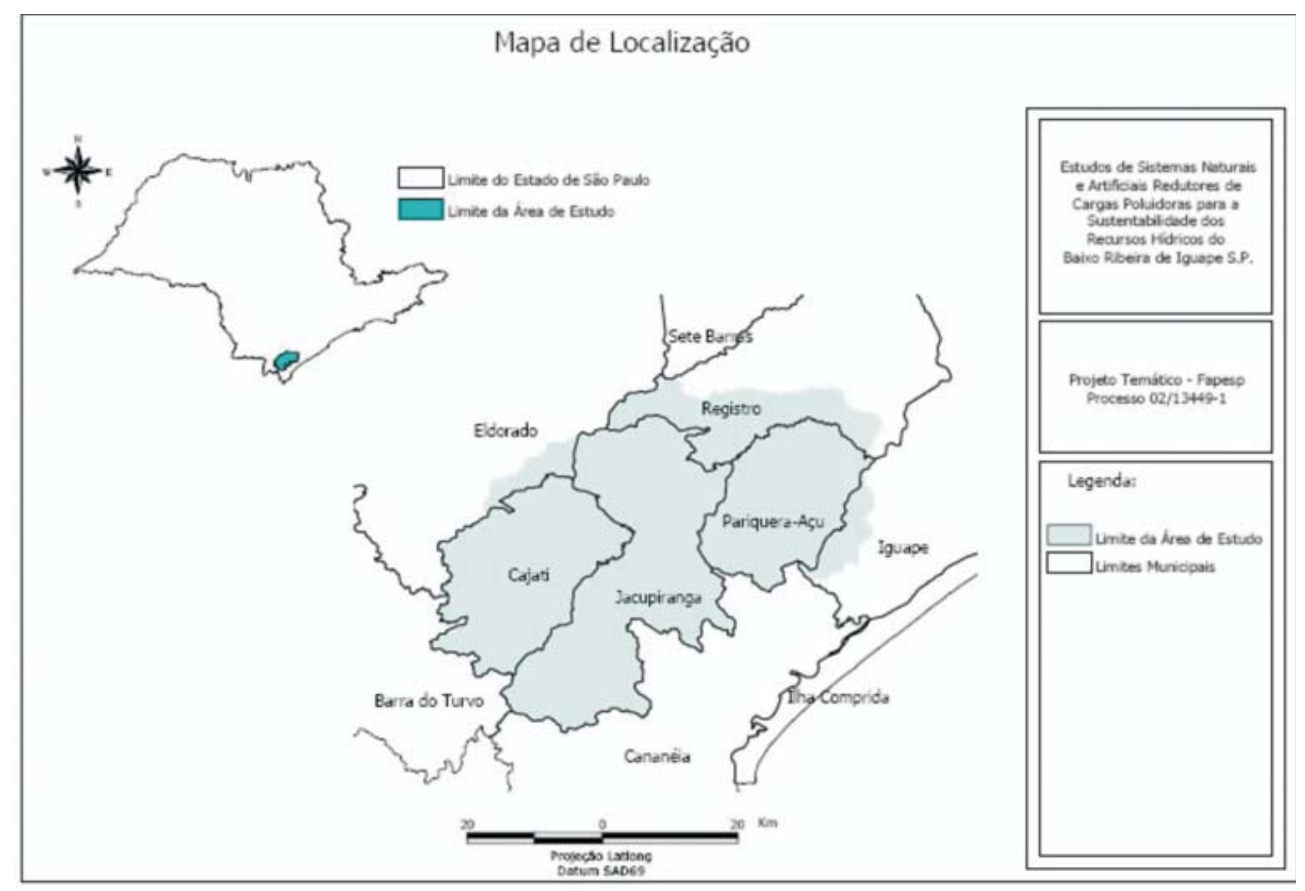

Figura I - Mapa de localização do Vale do Ribeira - SP

Tabela I - Dados de projeto da ETE Cajati (São Paulo, Brasil)

\begin{tabular}{cccccc}
\hline Lagoas & $\begin{array}{c}\text { Comprimento } \\
(\mathrm{m})\end{array}$ & $\begin{array}{c}\text { Largura } \\
(\mathrm{m})\end{array}$ & $\begin{array}{c}\text { Profundidade } \\
\text { máxima } \\
(\mathrm{m})\end{array}$ & $\begin{array}{c}\text { Volume útil } \\
\left(\mathrm{m}^{3}\right)\end{array}$ & $\begin{array}{c}\text { Tempo de } \\
\text { detenção } \\
\text { hidráulico (dias) }\end{array}$ \\
\hline Anaeróbia & 150,5 & 43,0 & 4,0 & $25.886,0$ & 5 \\
Facultativa & 210,0 & 173,0 & 1,5 & $5.4495,0$ & 24 \\
\hline
\end{tabular}

Fonte: SABESP Registro - SP 


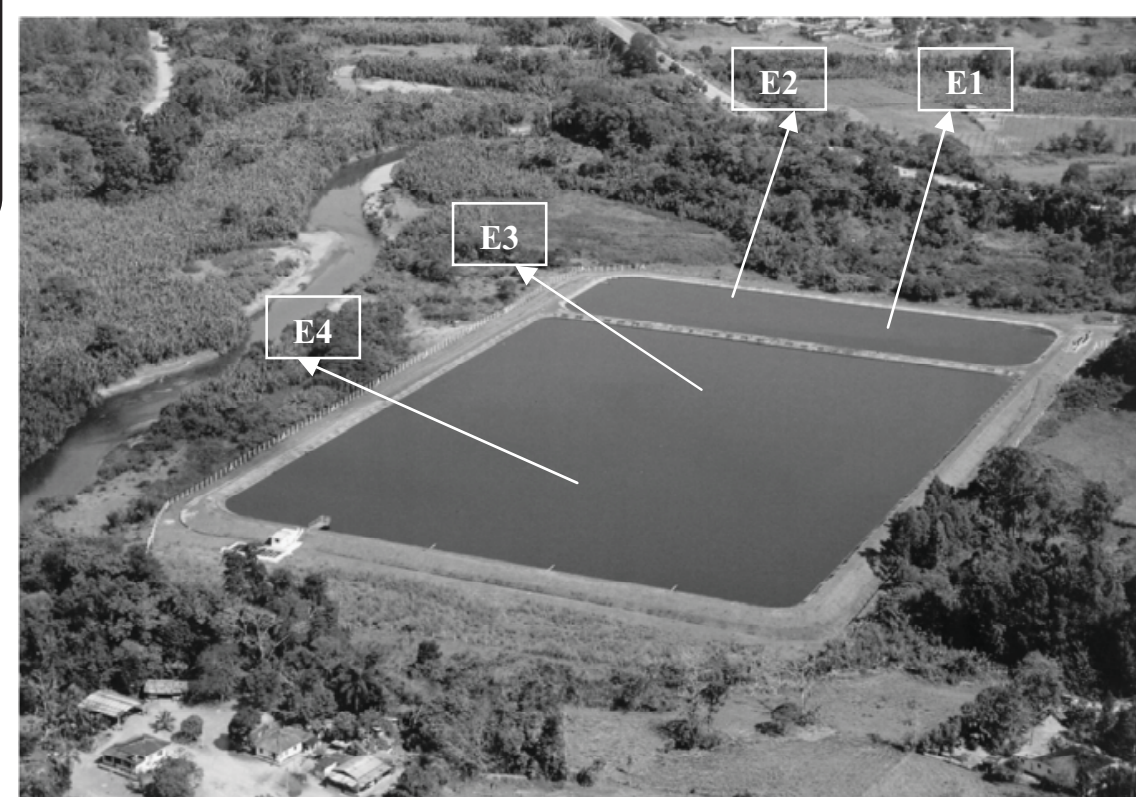

Figura 2 - Estação de tratamento de esgoto (ETE) de Cajati (SP) com as respectivas estações de amostragem - Projeto Fapesp n 02/I3449-I

\section{Análise estatística}

Os dados foram separados em dois estratos (superior e inferior) diferenciados física e quimicamente para tratamento estatístico pela técnica de Análise de Componentes Principais (ACP). Antes os dados foram transformados em log para estabilização da variância e diminuição do efeito de escala das respectivas variáveis (Legendre \& Legendre, 1998). A escolha dos fatores extraídos para interpretação foi baseada no critério clássico de Kaiser (1960), o qual define um valor mínimo $(\geq 1,0)$ para que um fator seja considerado como estatisticamente significativo. Os dados referentes ao horário T4 foram excluídos da análise em razão da tendência à isotermia e conseqüente homogeneização da coluna de água. Para realização das análises estatísticas utilizou-se o software Statistica 6.0. A interpretação dos resultados gerados baseou-se no exame dos planos fatoriais formados pelos respectivos eixos estatisticamente significativos, procurando associar cada fator a um processo metabólico específico. Vale ressaltar que as lagoas investigadas foram tratadas como sistemas individuais na ocasião da realização da ACP, visto que representam, essencialmente, processos metabólicos de naturezas diferentes.

\section{RESULTADOS E DISCUSSÃO}

A compartimentalização da coluna de água em dois estratos (superior e inferior) diferenciados física e quimicamente foi observada na maior parte do ciclo nictemeral. A Figura 3 mostra a estrutura térmica vertical nas lagoas anaeróbia e facultativa durante o ciclo de amostragem. A análise dos perfis verticais de temperatura revelou um padrão de estratificação e tendência à isotermia ao longo do ciclo nictemeral. Os maiores gradientes térmicos verticais foram observados no primeiro meio metro da coluna de água, dando origem a termoclinas bem definidas. $\mathrm{O}$ aquecimento diferencial da coluna de água durante o dia foi especialmente notado no horário T1 (14h), quando foram registrados gradientes máximos de $8,8^{\circ} \mathrm{C} / \mathrm{m}$ e $7,4^{\circ} \mathrm{C} / \mathrm{m}$ nas estações E2 (lagoa anaeróbia) e E4 (lagoa facultativa), respectivamente. A redução da temperatura do ar ao longo do ciclo de amostragem, com conseqüente resfriamento da superfície, resultou em menores gradientes verticais; no entanto, no horário T2 (20h), os gradientes ainda permaneceram bastante significativos, com valores correspondentes a $4,4^{\circ} \mathrm{C} / \mathrm{m}$ e $5,2^{\circ} \mathrm{C} / \mathrm{m}$ no primeiro metro nas estações E2 e E4, respectivamente. Nos horários T3 (2h), T0 (8h) e T4 (8h) a coluna de água apresentou gradientes térmicos reduzidos, com tendência à isotermia; fato particularmente observado no T4 (8h) na estação E2 (lagoa anaeróbia).

A ocorrência de estratificação térmica em sistemas de lagoas de estabilização resulta em compartimentos verticais metabolicamente diferenciados, onde a natureza e magnitude dos processos são governados pela disponibilidade e distribuição de recursos dissolvidos e particulados ao longo da coluna de água, em resposta à diferenciação física, química e biológica do sistema (Pearson et al, 1987; Curtis et al, 1994).

A estrutura térmica da coluna de água pareceu governar a distribuição vertical do oxigênio dissolvido (Figura 3), com a ocorrência de oxiclinas bem definidas nas profundidades correspondentes aos maiores gradientes térmicos. Concentrações típicas de supersaturação foram registradas na sub-superfície das estações E2 $(0,2 \mathrm{~m})$ e E3 $(0,3 \mathrm{~m})$ no horário T1 $(14 \mathrm{~h}): 10,4 \mathrm{mgO} \cdot \mathrm{L}^{-1}$ e $9,1 \mathrm{mgO}_{2} \cdot \mathrm{L}^{-1}$, respectivamente. As concentraçôes de oxigênio dissolvido permaneceram altas no primeiro metro da coluna de água na lagoa anaeróbia nos horários T1 (14h) e T2 (20h).

A estratificação térmica condicionou a formação de uma zona anóxica a partir do primeiro metro da coluna de água na lagoa facultativa, especialmente nos horários T1 (14h) e T2 (20h). Nos demais horários, a menor estabilidade da coluna de água causada pelo resfriamento da superfície durante a noite e primeiras horas do dia, resultou em menores gradientes de oxigênio dissolvido, embora a superfície da coluna de água permanecesse oxigenada. Uma exceção a este comportamento ocorreu no horário T4 $(8 \mathrm{~h})$, quando toda a coluna de água apresentou tendência a anoxia, com concentraçôes abaixo de $2,0 \mathrm{mgO} \cdot \mathrm{L}^{-1}$ até a profundidade de $0,5 \mathrm{~m}$, e nulas no restante do perfil. $\mathrm{O}$ déficit de oxigênio dissolvido observado no estrato superior da coluna de água a partir do horário T2 (20h) deveu-se ao seu consumo pelos processos de decomposição da matéria orgânica durante o ciclo escuro, quando não ocorre compensação através de produção pela atividade fotossintética do fitoplâncton (Kayombo et al, 2002).

Os gradientes de $\mathrm{pH}$ (Tabela 2 ) foram mais suaves em comparação àqueles observados para o oxigênio dissolvido. 
Os maiores valores foram registrados na lagoa facultativa, com máximo de 9,96 correspondente à sub-superfície da estação E4 no horário T1 (14h). Em todas as estações e horários amostrados houve tendência de diminuição do $\mathrm{pH}$ da sub-superfície à interface águasedimento. De modo geral, os valores de $\mathrm{pH}$ observados na lagoa anaeróbia estiveram dentro da faixa considerada ótima $(7,0-7,2)$ para a ocorrência do processo de fermentação anaeróbia.

Tadesse et al (2004) observaram picos nas variaçóes diurnas de temperatura, $\mathrm{pH}$ e oxigênio dissolvido na camada sub-superficial de um sistema piloto de lagoas de estabilização em um curtume na Etiópia, atribuindo tal comportamento ao aquecimento diferencial e às alteraçóes na atividade fotossintética do fitoplâncton decorrentes de mudanças nas condições climáticas ao longo do ciclo diário, especialmente na intensidade e disponibilidade de radiação fotossinteticamente ativa.

Os resultados de temperatura, $\mathrm{pH}$ e oxigênio dissolvido mostraram a compartimentalização das lagoas em dois estratos, um superior, delimitado pelo primeiro meio metro e caracterizado por elevados valores de $\mathrm{pH}$ e oxigênio dissolvido, e outro inferior, ocupando a maior parte da coluna de água, onde predominaram processos de decompo- sição da matéria orgânica, induzindo a menores valores de $\mathrm{pH}$ e tendência a anoxia, particularmente nos horários de maior estabilidade térmica. A boa oxigenação da superfície da lagoa anaeróbia, especialmente nos horários T0 (8h) e T1 (14h), deveu-se à atividade fotossintética do fitoplâncton, presente em densidades significativas quando comparadas àquelas encontradas na lagoa facultativa, onde essa comunidade teria, teoricamente, uma maior importância na produção de matéria orgânica autóctone, que serviria como substrato para a microbiota heterotrófica. A lagoa anaeróbia apresentou como valores máximo e mínimo de densidade fitoplanctônica $16,82 \times 10^{6}$ cel. $\mathrm{mL}^{-1}$ no horário T2 (interface água-sedimento) e $1,01 \times 10^{6}$ cel. $\mathrm{mL}^{-1}$ no horário T0 (interface água-sedimento) (Figura 4). A maior densidade na lagoa facultativa foi observada no horário T0, $5,65 \times 10^{6}$ cel. $\mathrm{mL}^{-1}$ (sub-superfície).

Em todos os horários amostrados houve predomínio de cianobactéria. Segundo Karl et al (2003), as cianobactérias são capazes de competir pelo nitrogênio, quando este está escasso, melhor que os outros grupos. As concentrações de nitrogênio amoniacal (Figura 5) estiveram baixas na lagoa facultativa. Ela também mostra as concentrações de proteína nas diferentes profundida- des amostradas. Em geral, estas foram maiores na sub-superfície das lagoas e menores na interface água-sedimento, comportamento antagônico ao observado para o nitrogênio amoniacal.

Observou-se nítida diminuição nas concentrações de nitrogênio amoniacal na lagoa facultativa em relação à anaeróbia, com concentração máxima correspondente à interface água-sedimento da estação E2 (20,2 mg. $\left.\mathrm{L}^{-1}\right)$ em T3 (2h), e mínima à sub-superfície da estação E4 (0,25 mg. $\left.\mathrm{L}^{-1}\right)$ em T1 (14h). As elevadas concentrações de nitrogênio amoniacal na lagoa anaeróbia, provavelmente, resultaram do acúmulo devido aos processos de mineralização da matéria orgânica, enquanto que a redução das concentrações na lagoa facultativa deveu-se, principalmente, à sua assimilação pela comunidade fitoplanctônica. Estes resultados corroboraram os obtidos por Santos e Oliveira (1987) e Senzia et al (2003), onde os primeiros autores observaram o fenômeno de mineralização da matéria orgânica com conseqüente aumento nas concentrações de nitrogênio amoniacal e ambos os trabalhos observaram a assimilação deste nitrogênio pela comunidade fitoplanctônica.

Segundo Picot et al (1992), a redução nas concentrações de nitrogênio amoniacal na superfície de lagoas de

Tabela 2 - Valores de pH correspondentes aos diferentes horários e profundidades amostradas nas lagoas nas lagoas anaeróbia e facultativa na ETE Cajati em abril/2005

\begin{tabular}{cccccc}
\hline $\begin{array}{c}\text { Horário de } \\
\text { amostragem }\end{array}$ & Profundidade & E1 & E2 & E3 & E4 \\
\hline T0 & S & 7,46 & 7,53 & 8,85 & 8,73 \\
& M & 7,11 & 7,00 & 8,68 & 7,98 \\
T1 & F & 6,88 & 6,93 & 7,90 & 7,20 \\
& S & 9,08 & 9,15 & 9,96 & 9,86 \\
& M & 7,11 & 7,21 & 9,34 & 9,39 \\
T2 & F & 7,01 & 6,91 & 8,21 & 7,44 \\
& S & 8,82 & 8,42 & 9,46 & 9,11 \\
& M & 7,11 & 7,06 & 9,32 & 8,89 \\
T3 & F & 6,84 & 6,84 & 7,55 & 7,56 \\
& S & 7,80 & 7,50 & 8,33 & 9,19 \\
& M & 7,05 & 7,00 & 8,10 & 8,87 \\
T4 & F & 6,81 & 6,84 & 7,41 & 7,16 \\
& S & 7,53 & 7,21 & 8,45 & 8,22 \\
& M & 7,00 & 6,91 & 8,42 & 7,95 \\
& F & 6,91 & 6,89 & 7,75 & 7,41 \\
\hline
\end{tabular}




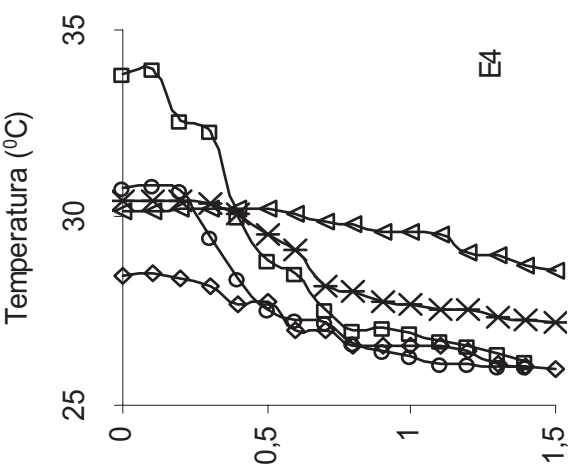

(w) әpep!punıodd

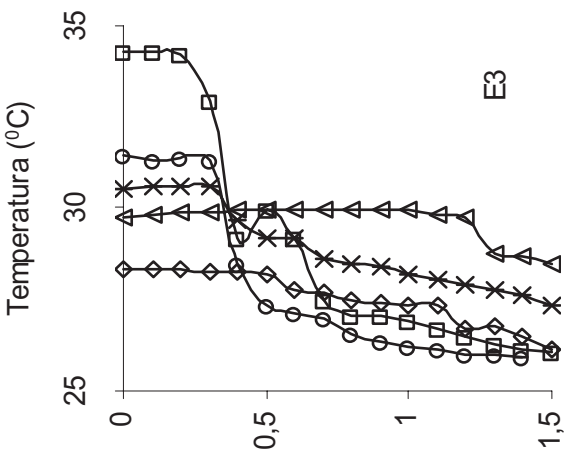

(u) әpep!punfodd

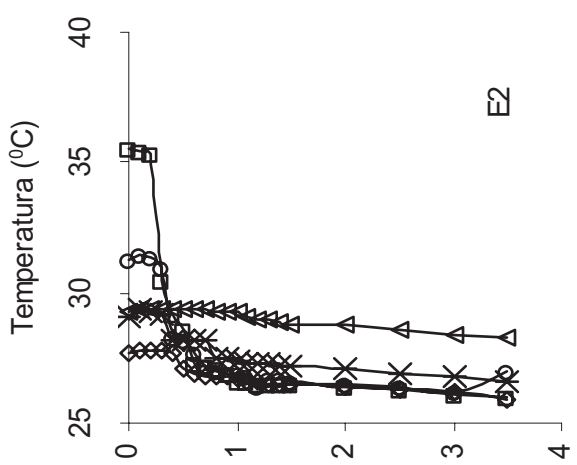

(u) әpep!punıodd

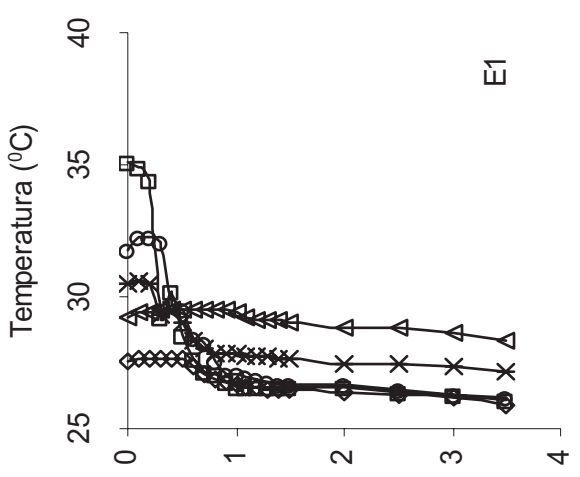

(u) әpep!punıodd

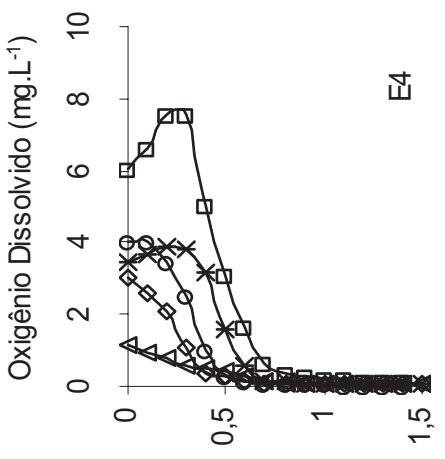

(u) әpep!punıodd

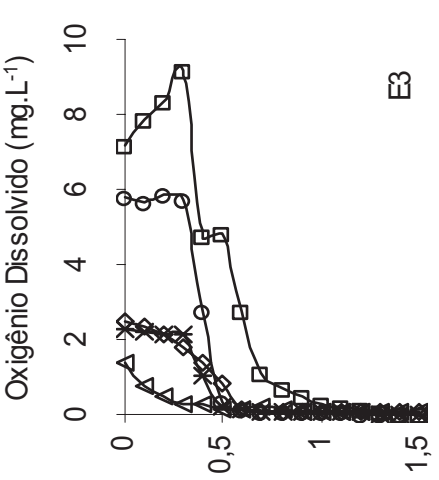

(u) әpep!punıold

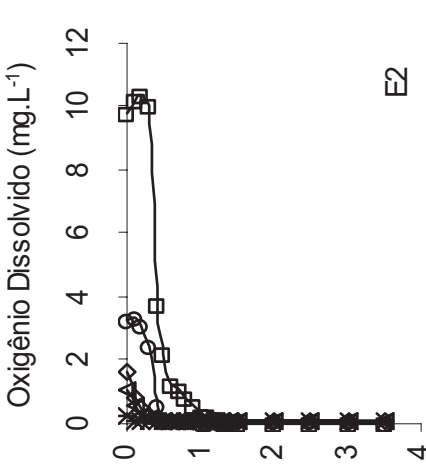

(w) әpep!punıold

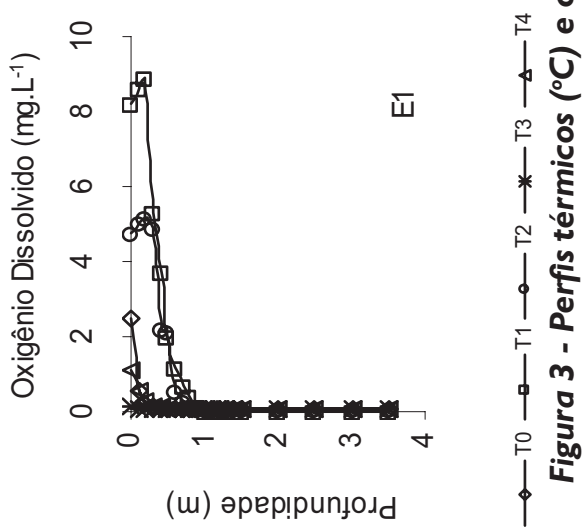

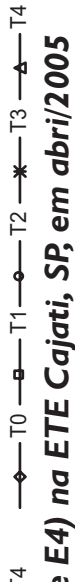

m

욜

$* \frac{\mathrm{T}}{\mathrm{S}}$

$\stackrel{5}{\circ}$

$\oint \frac{0}{\text { บิ }}$

F

느

은

|

氜

6.

कू

$*$

ํ.

\{

F

0.0

|

ชั

$\downarrow 0$

号

$*$.

蛋

१宁 (w) әpep!punıodd 


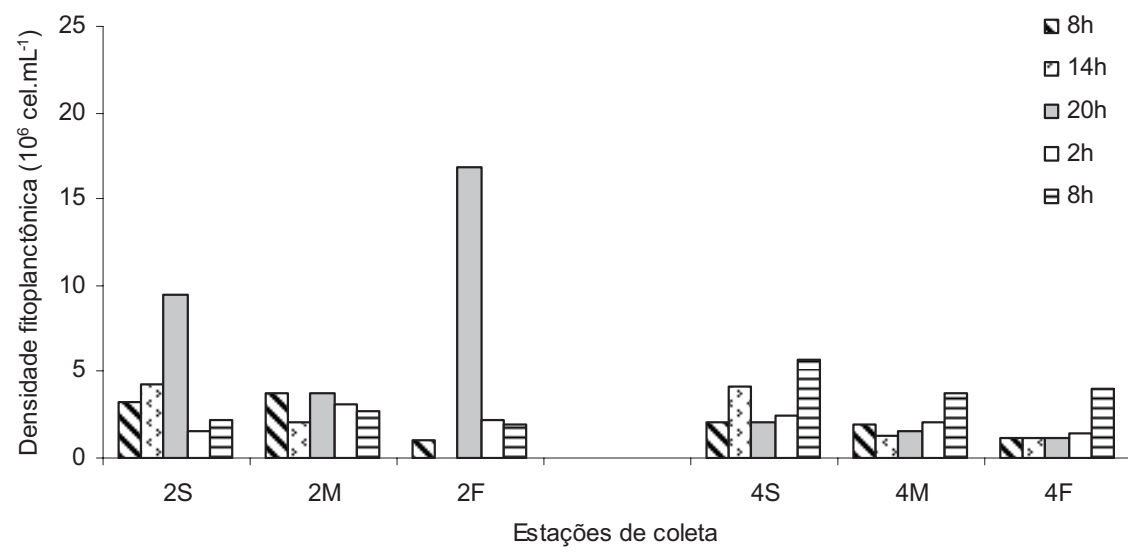

Figura 4 - Densidade fitoplanctônica $\left(10^{6} \cdot \mathrm{cel} . \mathrm{mL}^{-1}\right)$ nas diferentes profundidades das lagoas anaeróbia (E2) e facultativa (E4) na ETE Cajati - SP em abril/05
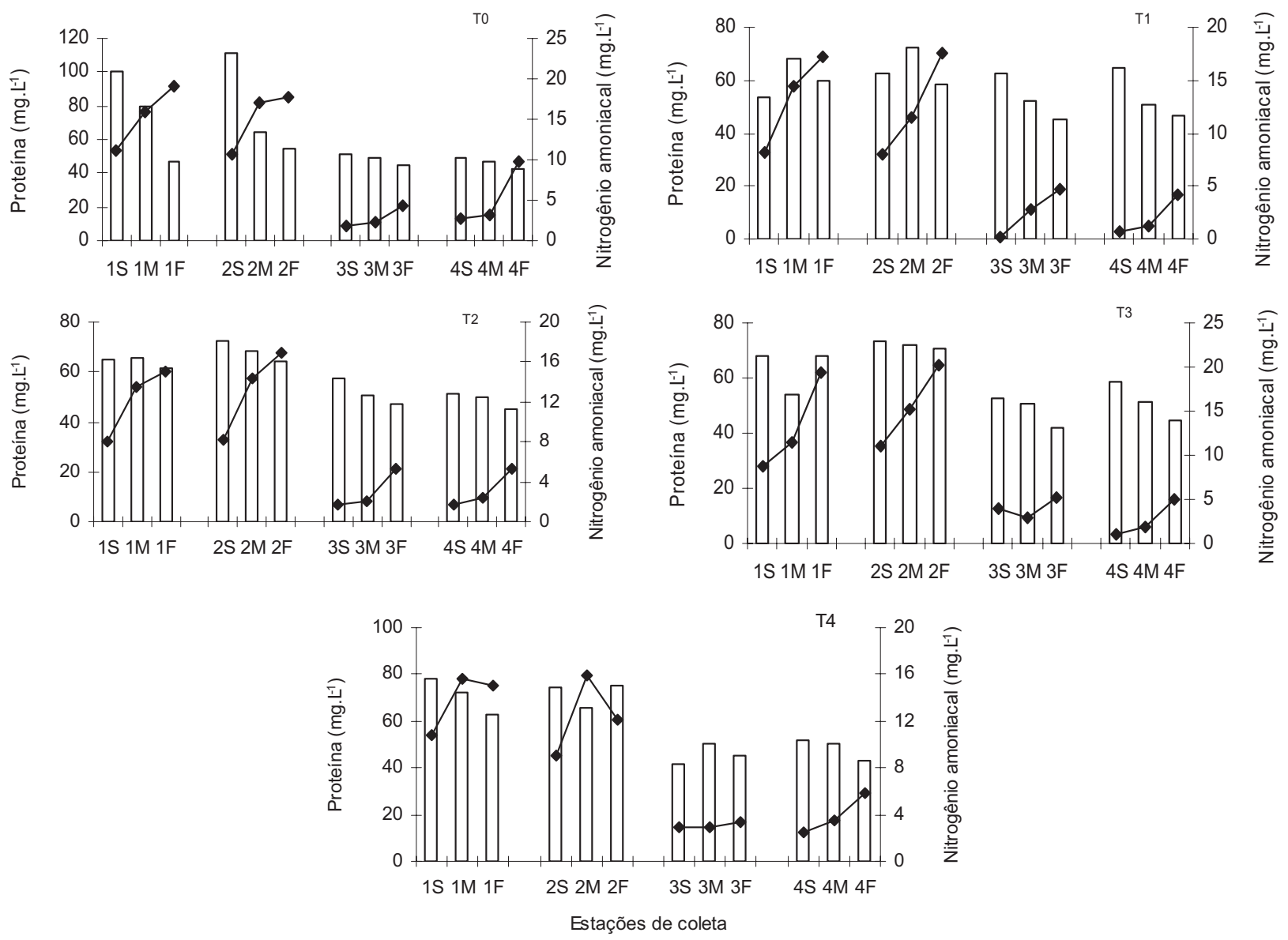

$\rightleftarrows$ Proteina $\multimap-\mathrm{N} \mathrm{NH3}$

Figura 5 - Concentrações de proteína $\left(m g \cdot L^{-1}\right)$ e nitrogênio amoniacal $\left(m g . L^{-1}\right)$ nos diferentes horários amostrados em abril/05 na ETE Cajati - SP 
estabilização deve-se principalmente à sua assimilação na forma de íon amônio, $\mathrm{NH}_{4}^{+}$, pelo fitoplâncton, embora também possa ocorrer perda da forma não-ionizada, $\mathrm{NH}_{3}$, como resultado do aumento de $\mathrm{pH}$ induzido pela atividade fotossintética.

As maiores concentrações de proteína foram observadas pela manhã (T0 e T4), com valor máximo detectado na sub-superfície da estação E2 (110,7 mg.L $\left.\mathrm{L}^{-1}\right)$ no horário T0 (8h). Santos \& Oliveira (1987) afirmaram que as concentrações de proteína são normalmente menores na lagoa anaeróbia devido aos processos de mineralização da matéria orgânica e sedimentação de sólidos suspensos, geralmente em elevadas concentraçóes neste tipo de sistema.

Para Tadesse et al (2004), as elevadas concentrações de nitrogênio amoniacal, normalmente detectadas junto ao fundo de lagoas de estabilização devem-se ao seu acúmulo, subseqüentemente à geração pelo processo de fermentação anaeróbia da matéria orgânica nitrogenada. De fato, observou-se diminuição nas concentrações de proteína em direção à interface águasedimento das duas lagoas investigadas, concomitantemente ao aumento nas concentraçôes de nitrogênio amonia- cal. A predominância de processos de decomposição da matéria orgânica no estrato inferior da coluna de água refletiu-se no padrão de distribuição vertical das variáveis $\mathrm{pH}$ e oxigênio dissolvido, as quais apresentaram tendência à diminuição em direção ao fundo das lagoas.

De modo geral, as concentraçôes de nitrato (Tabela 4) apresentaram pequena variação ao longo do sistema de tratamento e entre as profundidades amostradas. Observou-se máxima de 4,5 mg. $L^{-1}$ na sub-superfície da estação E1 no horário T1 (14h) e mínima de 1,5 mg. $\mathrm{L}^{-1}$ na interface água-sedimento da estação E4 no horário T4 (8h). Com relação ao nitrito, suas concentraçôes foram maiores na lagoa facultativa, atingindo 11,4 $\mu \mathrm{g} . \mathrm{L}^{-1}$ na sub-superfície da estação E4 em T3 (2h). Apesar do íon nitrito ser uma espécie cineticamente instável, constituindo-se num produto intermediário entre os processos de nitrificação e desnitrificação, as significativas concentraçóes na lagoa facultativa parecem ser indício de ocorrência de nitrificação, já que o nitrogênio amoniacal apresentou clara tendência à diminuição neste sistema. A menor concentração de nitrito foi detectada na lagoa anaeróbia, na estação E1, sub-

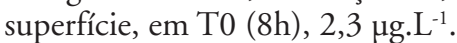

A ACP para os dados de superfície da lagoa anaeróbia extraiu três variáveis artificiais estatisticamente significativas, as quais explicaram cerca de $83,0 \%$ da variabilidade total dos dados. O primeiro fator (51,85\%; Figura 6) foi considerado representativo do processo de degradação de proteína, favorecida pela faixa ótima de $\mathrm{pH}$ e elevadas temperaturas observadas principalmente no horário T1 (14h) onde as concentrações de proteína estiveram menores na subsuperfície da lagoa anaeróbia. Segundo Peng et al. (2005) o nitrogênio orgânico é convertido a amoniacal sob ambas as condiçôes: anaeróbia e aeróbia. As elevadas concentrações de oxigênio dissolvido registradas no primeiro metro da coluna de água no horário T1 (14h) foram indicativas de alta atividade fotossintética do fitoplâncton neste compartimento durante o ciclo de luz. Esta característica peculiar pode ter interferido nas taxas de desnitrificação, normalmente altas nesse tipo de sistema e responsáveis pela remoção de nitrogênio através de perda para a atmosfera. Ao contrário, concentrações máximas de íons nitrato na sub-superfície dos pontos E1 (4,58 mg. $\left.\mathrm{L}^{-1}\right)$ e E2 $\left(2,98 \mathrm{mg} \cdot \mathrm{L}^{-1}\right)$ no horário T1 (14h) fortaleceram a hipótese de ocorrência do processo de nitrificação.

Tabela 4 - Concentrações de nitrato $\left(\mathrm{NO}_{3}^{-}\right)\left(\mathrm{mg} \cdot \mathrm{L}^{-1}\right)$ e nitrito $\left(\mathrm{NO}_{2}{ }^{-}\right)\left(\mu \mathrm{g} \cdot \mathrm{L}^{-1}\right)$ nos diferentes horários e profundidades em abril/05 na ETE Cajati - SP

\begin{tabular}{|c|c|c|c|c|c|c|c|c|c|}
\hline \multirow{2}{*}{$\begin{array}{l}\text { Horários de } \\
\text { amostragem }\end{array}$} & \multirow[t]{2}{*}{ Profundidade } & \multicolumn{2}{|c|}{ E1 } & \multicolumn{2}{|c|}{ E2 } & \multicolumn{2}{|c|}{ E3 } & \multicolumn{2}{|c|}{$\mathrm{E} 4$} \\
\hline & & $\mathrm{NO}_{3}^{-}$ & $\mathrm{NO}_{2}^{-}$ & $\mathrm{NO}_{3}^{-}$ & $\mathrm{NO}_{2}^{-}$ & $\mathrm{NO}_{3}^{-}$ & $\mathrm{NO}_{2}^{-}$ & $\mathrm{NO}_{3}^{-}$ & $\mathrm{NO}_{2}^{-}$ \\
\hline \multirow[t]{3}{*}{ T0 } & S & 2,93 & 2,32 & 2,85 & 4,84 & 2,69 & 6,59 & 2,3 & 7,54 \\
\hline & M & 2,4 & 4,63 & 2,68 & 3,44 & 2,28 & 5,98 & 2,26 & 4,73 \\
\hline & $\mathrm{F}$ & 2,74 & 3,05 & 2,64 & 2,96 & 2,2 & 4,89 & 2,22 & 3,23 \\
\hline \multirow[t]{3}{*}{$\mathrm{T} 1$} & $S$ & 4,57 & 3,12 & 2,98 & 4,52 & 2,37 & 7,43 & 2,28 & 10,02 \\
\hline & M & 2,09 & 4,56 & 2,61 & 5,82 & 2,41 & 7,43 & 2,21 & 8,16 \\
\hline & $\mathrm{F}$ & 2,88 & 2,61 & 2,84 & 3,2 & 2,29 & 6,17 & 2,16 & 5,03 \\
\hline \multirow[t]{3}{*}{$\mathrm{T} 2$} & $S$ & 2,49 & 4,33 & 2,62 & 4,22 & 2,24 & 10,14 & 2,32 & 9,44 \\
\hline & M & 2,91 & 4,73 & 2,78 & 4,22 & 2,32 & 9,78 & 1,88 & 6,97 \\
\hline & $\mathrm{F}$ & 3,15 & 3,57 & 2,87 & 4,15 & 2,38 & 5,27 & 2,33 & 5,94 \\
\hline \multirow[t]{3}{*}{ T3 } & $S$ & 2,58 & 3,82 & 2,35 & 4,57 & 2,85 & 7 & 2,23 & 11,42 \\
\hline & M & 2,87 & 4,8 & 2,6 & 6,11 & 2,28 & 8,91 & 2,22 & 10,83 \\
\hline & $\mathrm{F}$ & 2,6 & 4,3 & 1,72 & 3,4 & 2,26 & 7,81 & 2,34 & 3,02 \\
\hline \multirow[t]{3}{*}{$\mathrm{T} 4$} & $S$ & 2,58 & 4,35 & 2,52 & 3,21 & 2,11 & 3,15 & 2,09 & 5,92 \\
\hline & $\mathrm{M}$ & 2,83 & 3,47 & 2,71 & 4,31 & 2,13 & 3,21 & 1,96 & 4,86 \\
\hline & $\mathrm{F}$ & 2,73 & 3,51 & 2,52 & 2,62 & 1,71 & 2,92 & 2,26 & 3,71 \\
\hline
\end{tabular}




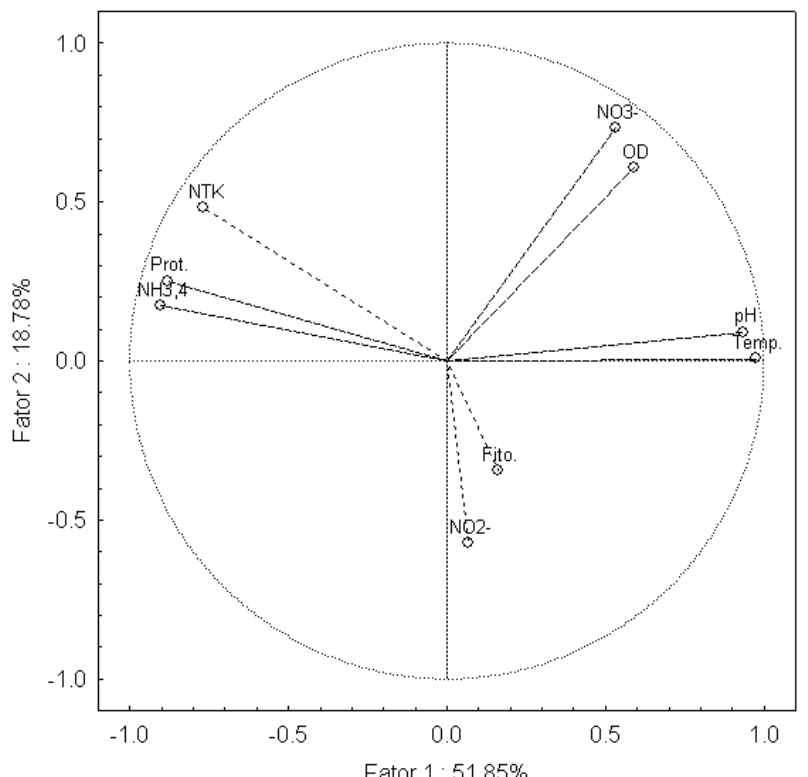

Figura 6 - Análise de Componentes Principais (ACP) para a sub-superfície da lagoa anaeróbia

O fator $2(18,78 \%)$ foi considerado representativo desse processo, evidenciando a correlação inversa entre os íons nitrito e as variáveis oxigênio dissolvido e íons nitrato. A entrada de esgoto bruto diluído deve ter contribuído para uma menor atividade heterotrófica na sub-superfície da coluna de água e favorecido a atividade de organismos fitoplanctônicos, responsáveis pela oxigenação deste compartimento durante o dia. Portanto, a baixa carga orgânica deve ter interferido na eficiência de remoção de matéria orgânica e nas perdas de nitrogênio por desnitrificação, comprometendo a eficiência do sistema e tornando-o, na prática, muito similar a uma lagoa facultativa.

No entanto, à medida que o nitrogênio amoniacal é gerado como produto primário da degradação de proteína, sua assimilação pelo fitoplâncton faz com que não haja acúmulo na superfície da coluna de água, resultando em concentraçôes menores que aquelas do fundo da lagoa. Além disso, há de se considerar a possível perda da fração não-ionizada $\left(\mathrm{NH}_{3}\right)$ do nitrogênio amoniacal por volatilização sob condições físicas favoráveis.

Da mesma forma, a ACP para os dados da interface água-sedimento da lagoa anaeróbia (Figura 7) retornou três fatores responsáveis pela explicação de cerca de $81,0 \%$ da variância dos dados. O fator I $(35,31 \%)$ representou, essencialmente, o processo de degradação de proteína pela biota heterotrófica. cesso de desnitrificação, favorecido pelas condições tipicamente redutoras do compartimento inferior da lagoa. $\mathrm{O}$ fator 3 (17,77\%; Figura 8) evidenciou a correlação inversa entre o nitrogênio amoniacal e as variáveis oxigênio dissolvido e íons nitrato. A ocorrência do processo de desnitrificação foi reforçada pela tendência à diminuição nas concentrações de íons nitrato e oxigênio dissolvido em direção ao fundo, concomitantemente ao aumento nas concentraçōes de íons nitrito e, especialmente, de nitrogênio amoniacal, na mesma direção.

Durante a noite, além da tendência a anoxia da coluna de água, observou-se redução significativa nas concentrações de íons nitrato na superfície da lagoa. Este comportamento foi particularmente evidenciado entre os horários T1 (14h) e T2 (20h) na estação E1, quando observou-se uma redução de 4,57 mg.L. $\mathrm{L}^{-1}$ para 2,49 mg.L. $\mathrm{L}^{-1}$. A estação E2 também apresentou a mesma tendência, embora houvesse uma redução mais discreta entre T1 e T3 (de 2,98 mg. $L^{-1}$ para 2,35 mg.L $L^{-1}$ ). Este comportamento suscitou a hipótese do íon nitrato ser utilizado como principal espécie aceptora de elétrons durante os processos de oxidação da matéria orgânica quando o oxigênio dissolvido encontra-se em baixas concentrações ou indisponível.

A ACP para os dados de superfície da lagoa facultativa (Figura 9) retornou 
três fatores estatisticamente significativos $(89,20 \%)$. O primeiro fator $(\approx 60,0 \%)$ foi considerado representativo do acoplamento entre os processos de decomposição e produção de matéria orgânica pelo consórcio alga-bactéria. Além das variáveis físicas temperatura e $\mathrm{pH}$, apresentaram correlação negativa com o fator 1 as variáveis proteína, oxigênio dissolvido e fitoplâncton.

No outro extremo do eixo, positivamente correlacionado, apareceu o nitrogênio amoniacal. Novamente aqui, as condições físicas do meio mostraram ter importância sobre a cinética de decomposição de proteína, através das variáveis temperatura e $\mathrm{pH}$. Na lagoa facultativa, a atividade fotossintética do fitoplâncton pareceu ter tido influência direta sobre o aumento dos valores de $\mathrm{pH}$ e a oxigenação da superfície da coluna de água. A elevada correlação entre proteína e fitoplâncton foi considerada como indicativo de síntese e excreção de proteína por essa comunidade, contribuindo efetivamente para o "pool" de matéria orgânica do sistema. A produção e excreção de nitrogênio extracelular por organismos fitoplanctônicos foram observadas por Stewart (1980) em culturas puras. A liberação destes compostos, incluindo aminoácidos, peptídeos, aminas, polipeptídeos e proteínas, é fortemente influenciada pelas condiçóes de temperatura e $\mathrm{pH}$, já que estas variáveis condicionam a cinética dos processos metabólicos que têm lugar em lagoas de estabilização. Segundo Bronk et al (1994), no fitoplâncton, cerca de $25-41 \%$ do nitrogênio inorgânico dissolvido (NID) assimilado pode ser rapidamente liberado de volta para a coluna de água na forma de nitrogênio orgânico dissolvido (NOD). Segundo Flynn \& Berry (1999), muito deste NOD liberado pode estar na forma de aminoácidos combinados.

A correlação inversa do fator 1 com a variável nitrogênio amoniacal indicou a assimilação preferencial deste nutriente (produto primário da degradação de proteína) pelo fitoplâncton. A perda de nitrogênio amoniacal por volatilização da forma não-ionizada $\mathrm{NH}_{3}$ também foi suscitada, já que os valores de $\mathrm{pH}$ na lagoa facultativa estiveram, ordinariamente, acima de 7,0, com valor extremo de 9,96. Apesar do nitrogênio amoniacal encontrar-se predominantemente na forma ionizada, $\mathrm{NH}_{4}^{+}$, na faixa de $\mathrm{pH}$ observada, a ação sinérgica desta variável com

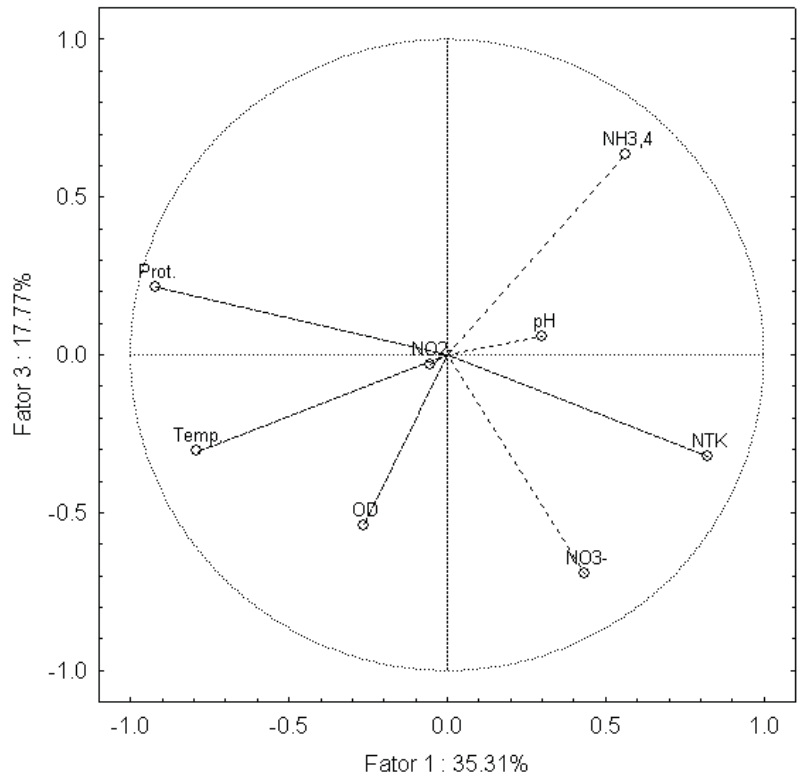

Figura 8 - Análise de Componentes Principais (ACP) para a interface água-sedimento da lagoa anaeróbia

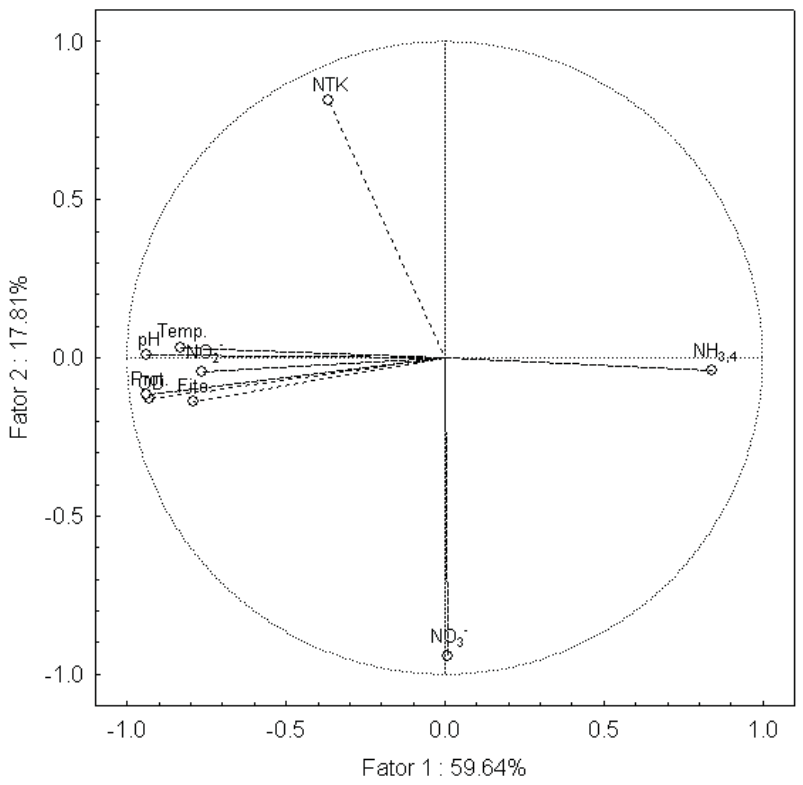

Figura 9 - Análise de Componentes Principais (ACP) para a sub-superfície da lagoa facultativa

a temperatura pode ter resultado na volatilização de parte da fração nãoionizada, especialmente nos horários de maior insolação.

De acordo com Reed (1985), a remoção de nitrogênio amoniacal em sistemas de lagoas de estabilização é dependente da ação sinérgica entre $\mathrm{pH}$ e temperatura. Segundo Peng et al (2005), estas duas variáveis têm impacto direto sobre o metabolismo da microbiota e sobre a volatilização de $\mathrm{NH}_{3}$, sendo que as elevadas temperaturas normalmente encontradas durante o dia induzem à maiores velocidades de mineralização da matéria orgânica, com conseqüente disponibilização de nitrogênio amoniacal para o fitoplâncton, $o$ qual provoca um aumento do $\mathrm{pH}$ do meio pelo consumo de dióxido de carbono dissolvido durante a fotossíntese. Este quadro pode favorecer a perda de $\mathrm{NH}_{3}$ por volatilização durante o ciclo de luz. Zimmo (2003b) observaram que a remoção de nitrogênio em sistemas simulando lagoas de estabilização colonizadas por fitoplâncton e macrófitas aquáticas teve maior dependência do 
$\mathrm{pH}$ do que das concentrações de oxigênio dissolvido. Estes pesquisadores observaram maior eficiência de remoção de nitrogênio quando os valores de $\mathrm{pH}$ estiveram entre 7,0 e 9,0. O segundo fator $(17,81 \%)$, extraído da ACP para os dados de superfície da lagoa facultativa, apesar de não estar muito bem esclarecido, foi associado ao processo de nitrificação, já que apresentou forte correlação negativa com os íons $\mathrm{NO}_{3}^{-} \mathrm{e}$ positiva com nitrogênio total kjeldahl.

Os resultados da ACP para os dados correspondentes à interface água-sedimento da lagoa facultativa apresentaram-se muito similares àqueles da lagoa anaeróbia, representando, essencialmente, os mesmos processos.

\section{CONCLUSÕES}

A forte estratificação térmica resultou do aquecimento da superfície, sem posterior redistribuição do calor ao longo da coluna de água durante o dia e primeiras horas da noite, quando ainda foram registrados gradientes térmicos significativos. A estrutura térmica vertical condicionou a ocorrência de estratificação química nas duas lagoas. A compartimentalização vertical resultante foi caracterizada pela presença de um estrato superior bem oxigenado, particularmente durante o dia, inclusive na lagoa anaeróbia, favorecendo o processo de nitrificação, conforme revelado pela análise de ACP. A entrada de esgoto diluído nesta lagoa deve ter favorecido o desenvolvimento do fitoplâncton na superfície em detrimento da atividade heterotrófica bacteriana e da desnitrificação, processo responsável pela remoção de nitrogênio neste tipo de sistema através de perdas por volatilização. No entanto, a decomposição de proteína pela microbiota heterotrófica foi bem caracterizada no estrato inferior das duas lagoas, com o íon nitrato sendo considerado como aceptor alternativo de elétrons quando em condições anóxicas. A possível excreção de proteína pela comunidade fitoplanctônica no estrato superficial da lagoa facultativa também foi outro processo metabólico evidenciado pela ACP, a qual mostrouse uma ferramenta particularmente útil para a visualização das transformações envolvidas na dinâmica do nitrogênio em lagoas de estabilização. Além da importância dos aspectos climáticos, a dinâmica do nitrogênio e, conseqüentemente, sua remoção, está diretamente relacionada à operação do sistema de lagoas, particularmente ao tempo de detençãao hidráulico. Esta variável hidrodinâmica, juntamente com as condiçôes atmosféricas locais, define o grau de mistura do afluente com a água residuária residente e, portanto, a estrutura vertical da coluna de água, além da magnitude dos processos de decomposição, produção e sedimentação. Desta forma, a eficiência de remoção do nitrogênio pelo sistema de lagoas de estabilização do município de Cajati é dependente não somente das variaçôes climáticas ao longo do ciclo diário, como da otimização do sistema através da manipulação de variáveis hidrodinâmicas. Além disso, deve-se avaliar a taxa de infiltração na rede antes do esgoto entrar no sistema, visto que a baixa carga orgânica implicou em semelhança de funcionamento entre as lagoas anaeróbia e facultativa.

\section{AGRADECIMENTOS}

Os autores agradecem a Fapesp pela concessão dos recursos ao Projeto Temático processo no 02/13449-1 e pela bolsa de doutorado processo no $03 / 06796-0$.

\section{REFERÊNCIAS}

APHA - AMERICAN PUBLIC HEALTH ASSOCIATION. Standard Methods for Examination of Water and Wastewater. 20 th edition. Washington. 1999.

BRONK, D. A., GLIBERT, P. M., AND WARD, B. B. Nitrogen uptake, dissolved organic nitrogen release, and new production, Science, v. 265 , p. $1843-1846.1994$.

CIIAGRO - CENTRO INTEGRADO DE INFORMACÕES METEOROLÓGICAS - INSTITUTO AGRONÔMICO DE CAMPINAS - Balanço Hídrico da regiāo do Vale do Ribeira. Governo do Estado de São Paulo. http://ciiagro.iac.sp.gov.br/ciiagroonline/. Acesso em 02/09/2005.

\section{CETESB - COMPANHIA DE TECNOLOGIA} DE SANEAMENTO AMBIENTAL. Relatório de Qualidade das Águas Interiores do Estado de São Paulo 2003. http://www.cetesb.sp.gov.br. Acesso em 12/05/2004.

CURTIS, T. P.; et al. Light penetration in waste stabilization ponds. Wat. Res., v. 28 , n. 5 , p. 1031-1038. 1994.

FERRARA, R. A.; AVCI, C.B. Nitrogen dynamics in waste stabilization ponds. Journal of water pollution control federation, v.54, n.4, p. 361-369. 1982.

FLYNN, K. J., BERRY, .L. S. The loss of organic nitrogen during marine primary production may be significantly overestimated when using $N-15$ substrates, 175 Proceedings of the Royal Society of London Series B-Biological Sciences, v. 266, n. 1419, p.641-647. 1999.

KAISER, H. F. The application of electronic computers to factor analysis. Educational and Psychological Measurement, 20, p. 141-151. 1960.

KARL, E. H.; et al. N:P ratios, ligh limitation, and cyanobacterial dominance in a subtropical lake impacted by non-point source nutrient pollution. Environmental Pollution, v. 122, p. 379-390. (2003).

KAYOMBO, S.; et al. Diurnal cycles of variations of physical-chemical parameters in waste stabilization ponds. Ecological Engineering, v. 18, n. 3, p. 287-291. 2002.

LEGENDRE, P. \& LEGENDRE, L. Numerical Ecology. Elsevier Science B.V., Amsterdam, 853 p. 1998.

LOWRY, O.H.; et al. Protein measurement with the Folin phenol reagent. J. Biol. Chem. v. 193, p. 265-276. 1951.

MIETTINEN, T.; et al. Multivariate monitoring of a biological wastewater treatment process: a case study at Melbourne Water's Western Treatment Plant. Chemometrics and Intelligent Laboratory Systems, v. 73, p. 131-138. 2004.

MIDDLEBROOKS, E. J.; et al. Wastewater Stabilization Lagoon Design, Performance and Upgrading. Macmillan Publishing, New York, N. Y. 1982.

PEARSON, H. W.; MARA, D. D.; BARTONE, C. R. Guidelines for the minimum evaluation of the performance of full-scale waste stabilization pond systems. Water Research, v. 21, n. 9, p. 1067-1075. 1987.

PENG, J. F.; WANG, B. Z.; WANG, L. Mult-stage ponds-wetlands ecosystem for effective wastewater treatment. Journal of Zhejiang University Science, v. 6B, n. 5, p. 346-352. 2005.

PICOT, B.; et al. Comparison of the purifying efficiency of high rate algal pond with stabilization pond. Water Science and Technology, v. 25, n. 12, p. 197-206. 1992.

REED, S. C. Nitrogen removal in wastewater stabilization ponds. Journal of Water Pollution Control Federation, v. 57, n. 1, jan 1985.

SABESP - Dados do Sistema Regional do Vale do Ribeira. www.sabesp.com.br. Acesso em 11 de abril de 2005.

SANTOS, M. C. R., OLIVEIRA, J. F. S. Nitrogen transformations and removal in waste stabilization ponds in Portugal: seasonal variations. Wat. Sci. Tech., v. 19, n. 12, p. 123-130. 1987.

SENZIA, M. A.; MASHAURI, D. A.; MAYO, A.W. Suitability of constructed wetlands and waste stabilization ponds in wastewater treatment nitrogen transformation and removal. Physics and Chemistry of the Earth, v. 28, p. 1117-1124. 2003

SILVA, S. A.; et al. Nitrogen removal in pond systems with different configurations and geometries. Wat. Sci. Tech., v. 31, n. 12, p. 321-330, 1995.

STEWART, W. D. P. Transport and utilization of nitrogen sources by algae. Chap. 4.5. p. 577-607. In: PAYNE, J. W. (1980). Microorganisms and nitrogen sources. John Wiley \& Sons Ltd. 1980.

TADESSE, I.; GREEN, F. B.; PUHAKKA, J. A. Seasonal and diurnal variations of temperature, 
Miwa, A. C. P.; Freire, R.H. F.; Calijuri, M. C.

pH and dissolved oxygen in advanced integrated wastewater pond system treating tannery effluent.

Water Research, v. 38, p. 645-654, 2004.

ZIMMO, O. R.; VAN DER STEEN, N. P.

GIJZEN, H. J. Comparison of ammonia volatilization rates in algae and duckweed-based waste stabilization ponds treating domestic wastewater. Water Research, v. 37, p. 4587-4594, 2003 .

ZIMMO, O. R. Nitrogen transformations and removal mechanisms in algal and duckweed waste stabilization ponds. Publisher: A. A. Balkema Publishers, a member of Swets \& Zeitlinger Publishers. 144 p. 2003 b.

WETZEL, R. G. \& LIKENS, G. E. Limnological analyses. 2 ed. New York Sringer, 391 p. 1991.

Endereço para correspondência:

Adriana Cristina Poli Miwa

Departamento de Hidráulica e

Saneamento

Escola de Engenharia de São

Carlos - USP

Av. Trabalhador São-carlense, 400

I 3566-590 São Carlos - SP - Brasil

Tel: (I6) 3373-9427

E-mail: adriana_miwa@yahoo.com.br 